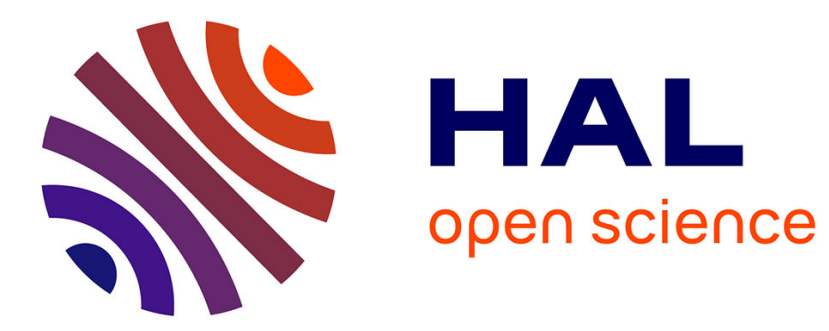

\title{
Optical properties of Ag- and AgI-doped Ge-Ga-Te far-infrared chalcogenide glasses
}

Ci Cheng, Xunsi Wang, Tiefeng Xu, Lihong Sun, Zhanghao Pan, Shuo Liu, Qingde Zhu, Fangxing Liao, Qiuhua Nie, Shixun Dai, et al.

\section{- To cite this version:}

Ci Cheng, Xunsi Wang, Tiefeng Xu, Lihong Sun, Zhanghao Pan, et al.. Optical properties of Agand AgI-doped Ge-Ga-Te far-infrared chalcogenide glasses. Infrared Physics and Technology, 2016, 76, pp.698-703. 10.1016/j.infrared.2016.04.035 . hal-01341574

HAL Id: hal-01341574

https://hal-univ-rennes1.archives-ouvertes.fr/hal-01341574

Submitted on 8 Jul 2016

HAL is a multi-disciplinary open access archive for the deposit and dissemination of scientific research documents, whether they are published or not. The documents may come from teaching and research institutions in France or abroad, or from public or private research centers.
L'archive ouverte pluridisciplinaire HAL, est destinée au dépôt et à la diffusion de documents scientifiques de niveau recherche, publiés ou non, émanant des établissements d'enseignement et de recherche français ou étrangers, des laboratoires publics ou privés. 


\title{
Optical properties of Ag- and AgI-doped Ge-Ga-Te far-infrared
}

\section{chalcogenide glasses}

\author{
Ci Cheng ${ }^{1}$, Xunsi Wang ${ }^{1 *}$, Tiefeng Xu ${ }^{1}$, Lihong $\operatorname{Sun}^{1}$, Zhanghao Pan ${ }^{1}$, Shuo Liu ${ }^{1}$, Qingde Zhu ${ }^{1}$, \\ Fangxing Liao ${ }^{1}$, Qiuhua $\mathrm{Nie}^{1}$, Shixun Dai ${ }^{1}$, Xiang Shen $^{1}$, Xianghua Zhang ${ }^{2}$, Wei Chen ${ }^{3 *}$ \\ ( ${ }^{1}$ Laboratory of Infrared Material and Devices, The Research Institute of Advanced Technologies, Ningbo University, Ningbo, Zhejiang \\ 315211, China) \\ ( ${ }^{2}$ Laboratory of Glasses and Ceramics, UMR 6226 CNRS-University of Rennes 1, Rennes Cedex 135042, France) \\ ( ${ }^{3}$ Department of Electrical Engineering, Shaoyang University, Shaoyang, Hunan 422004, China)
}

\begin{abstract}
Te-based glasses are ideal material for life detection and infrared-sensing applications because of their excellent far-infrared properties. In this study, the influence of Ag- and AgIdoped Te-based glasses were discussed. Thermal and optical properties of the prepared glasses were evaluated using X-ray diffraction, differential scanning calorimetry, and Fourier transform infrared spectroscopy. Results show that these glass samples have good amorphous state and thermal stability. However, $\mathrm{Ge}-\mathrm{Ga}-\mathrm{Te}-\mathrm{Ag}$ and $\mathrm{Ge}-\mathrm{Ga}-\mathrm{Te}-\mathrm{AgI}$ glass systems exhibit completely different in optical properties. With an increase of Ag content, the absorption cut-off edge of $\mathrm{Ge}-\mathrm{Ga}-\mathrm{Te}-\mathrm{Ag}$ glass system has a red shift. On the contrary, a blue shift appears in $\mathrm{Ge}-\mathrm{Ga}-$ $\mathrm{Te}-\mathrm{AgI}$ glass system with an increase of $\mathrm{AgI}$ content. Moreover, the transmittance of $\mathrm{Ge}-\mathrm{Ga}-$ $\mathrm{Te}-\mathrm{Ag}$ glass system deteriorates while that of $\mathrm{Ge}-\mathrm{Ga}-\mathrm{Te}-\mathrm{AgI}$ glass system ameliorates. All glass samples have wide infrared transmission windows and the far-infrared cut-off wavelengths of these glasses are beyond $25 \mu \mathrm{m}$. The main absorption peaks of these glasses are eliminated through a purifying method.
\end{abstract}

Keywords: far-infrared; Te-based glasses; thermal stability; infrared transmission windows

\section{Introduction}

Chalcogenide glasses have unique advantages in infrared (IR) applications, especially in far-IR [1-11]. The far-IR cut-off wavelength of Te glass is usually greater than $20 \mu \mathrm{m}$. However, most $\mathrm{Te}$ glasses are unstable against crystallization because of strong metallic properties of $\mathrm{Te}$ atoms. Some electron-deficient additives, such as $\mathrm{Ge}, \mathrm{Ga}$, and I atoms, are doped into glass to improve the thermal stability and optical properties of Te-based chalcogenide glasses. Zhang et al. [1] proposed that elemental halogen doped into glass can open up the original network structure and improve the ability of glass formation. Nevertheless, the weak mechanical and low thermal characteristics of $\mathrm{Te}-\mathrm{X}(\mathrm{Cl}, \mathrm{Br}, \mathrm{I})$ glasses limit the glasses to be fabricated as fibers or shaped into lenses. To overcome these limitations, many scientists exerted their efforts to develop suitable Te-based glasses. Wilhelm et al. [5] reported that Ge-Te-I ternary glass system has good thermal stability and wide IR transparency window, but elemental I can volatilize easily during the fiber fabrication. Maurugeon et al. [12] revealed that Ge-Te-Se chalcogenide glasses have good glassforming ability and high IR transmission. However, the IR cut-off edge is limited by Se atoms. Danto et al. [3] reported that the IR cut-off edge of $\mathrm{Ge}-\mathrm{Ga}-\mathrm{Te}$ glass system is beyond 25 $\mu \mathrm{m}$, but the IR transmission spectrum has an obvious absorption band. Ramesh et al. [13] reported

\footnotetext{
${ }^{*}$ Corresponding author. Fax: +86 57487600947.

E-mail address: xunsiwang@siom.ac.cn (X.Wang).
} 
that metal can improve connectivity of glass and stabilize glass structure. Recently, Sun et al. [14] proposed that halide can improve the abilities of glass formation and anti-crystallization. To date, comprehensive study about the different influence of Ag- and AgI-doped Ge-Ga-Te glasses has not been reported.

In our study, $\mathrm{Ge}-\mathrm{Ga}-\mathrm{Te}-\mathrm{Ag}$ and $\mathrm{Ge}-\mathrm{Ga}-\mathrm{Te}-\mathrm{AgI}$ glass samples were prepared by traditional melt-quenching method. This work aims to analyze different optical properties of two kinds of glass systems. This is the first comprehensive study to discuss the optical properties of metal- and metal halide-doped Te-based glasses. Thermal and optical properties were tested by differential scanning calorimetry (DSC) and Fourier transform IR spectroscopy (FTIR).

\section{Experimental}

For this experiment, $\left(\mathrm{Ge}_{15} \mathrm{Ga}_{10} \mathrm{Te}_{75}\right)_{100-\mathrm{x}}(\mathrm{Ag})_{\mathrm{x}}(\mathrm{x}=10,20,30,40)$ glasses (named GGT-Ag10, GGT-Ag20, GGT-Ag30, and GGT-Ag40, respectively) and $\left(\mathrm{Ge}_{15} \mathrm{Ga}_{10} \mathrm{Te}_{75}\right)_{100-\mathrm{x}}(\mathrm{AgI})_{\mathrm{x}}(\mathrm{x}=10,20$, 30, 40) glasses (named GGT-AgI10, GGT-AgI20, GGT-AgI30, and GGT-AgI40, respectively) were prepared and investigated. Appropriate amounts of raw materials $\mathrm{Ge}, \mathrm{Ga}, \mathrm{Te}, \mathrm{Ag}$, and $\mathrm{AgI}$ with high purity were weighed carefully and transferred into quartz ampoules. The ampoules were sealed under vacuum $\left(\sim 10^{-3} \mathrm{~Pa}\right)$ and melted in a rocking furnace at $850^{\circ} \mathrm{C}$ for $15 \mathrm{~h}$ to homogenize the mixtures. The ampoules were then swiftly quenched in ice water and annealed at $10{ }^{\circ} \mathrm{C}$ below glass transition temperature $\left(T_{\mathrm{g}}\right)$ for $5 \mathrm{~h}$ in several prepared furnaces to eliminate inner stress of glasses. Finally, glass samples were cut into discs and polished for testing.

The amorphous nature of glass samples were elucidated by X-ray diffraction (XRD, German Bruker D2) and scanning electron microscopy (SEM). Thermal parameters were measured through DSC with the temperature ranging from $50{ }^{\circ} \mathrm{C}$ to $400{ }^{\circ} \mathrm{C}$ at a heating rate of $10{ }^{\circ} \mathrm{C} / \mathrm{min}$ by a TAQ2000 thermal analyzer. The visible to near-IR spectra were recorded using PerkinElmer Lambda 950 UV-Vis-NIR spectrophotometer. FTIR spectra were obtained using Nicolet 380 FTIR from $4000 \mathrm{~cm}^{-1}$ to $400 \mathrm{~cm}^{-1}$. All optical tests were performed at room temperature.

\section{Results and discussion}

\subsection{Amorphous nature analysis}

The glass-forming ability of chalcogenide glass is usually evaluated by the amorphous state. Fig. 1 shows the typical XRD patterns of $\mathrm{Ge}-\mathrm{Ga}-\mathrm{Te}-\mathrm{Ag}$ and $\mathrm{Ge}-\mathrm{Ga}-\mathrm{Te}-\mathrm{AgI}$ glass samples. As presented in Fig. 1, there is no obvious crystallization peak in the curves. To ensure the absence of microcrystals in these glasses, a structural study using SEM was also performed to confirm the amorphous state. Fig. 2 shows that the surfaces of these glass samples are nearly homogeneous with no obvious microcrystals. All results indicate that $\mathrm{Ge}-\mathrm{Ga}-\mathrm{Te}-\mathrm{Ag}$ and $\mathrm{Ge}-\mathrm{Ga}-\mathrm{Te}-\mathrm{AgI}$ glass systems maintain their amorphous nature. 


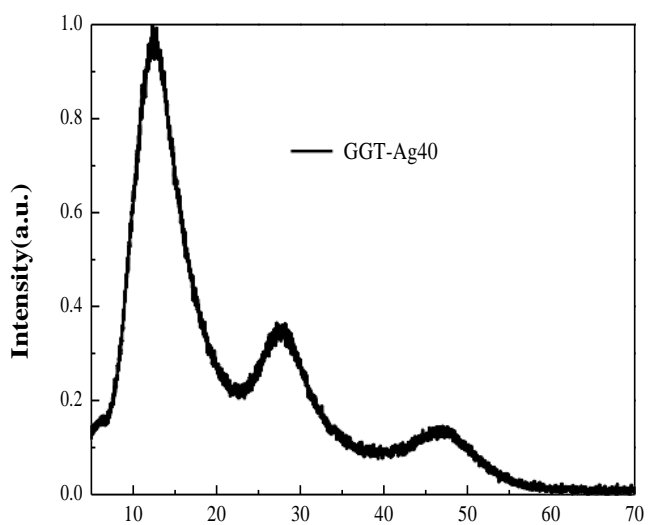

(a) Diffraction $(2 \theta)$

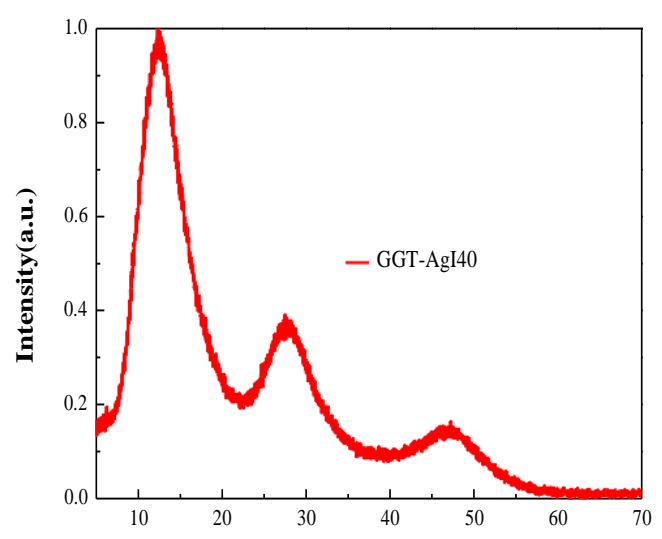

(b) Diffraction $(2 \theta)$

Fig. 1. XRD patterns of powder glass samples: (a) $\left(\mathrm{Ge}_{15} \mathrm{Ga}_{10} \mathrm{Te}_{75}\right)_{60}(\mathrm{Ag})_{40}$ and (b) $\left(\mathrm{Ge}_{15} \mathrm{Ga}_{10} \mathrm{Te}_{75}\right)_{60}(\mathrm{AgI})_{40}$.
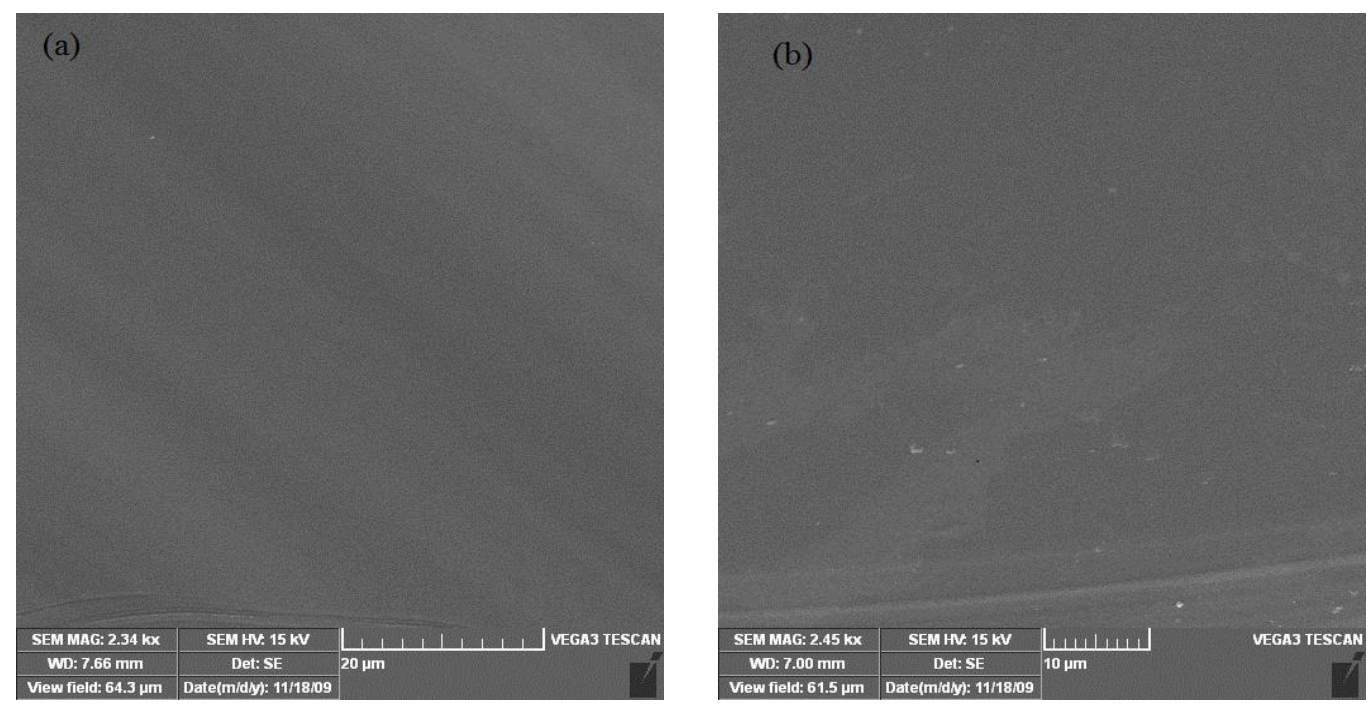

Fig. 2. SEM images of typical glass samples: (a) $\left(\mathrm{Ge}_{15} \mathrm{Ga}_{10} \mathrm{Te}_{75}\right)_{60}(\mathrm{Ag})_{40}$ and (b) $\left(\mathrm{Ge}_{15} \mathrm{Ga}_{10} \mathrm{Te}_{75}\right)_{60}(\mathrm{AgI})_{40}$.

\subsection{Thermal properties analysis}

The thermal parameters of these chalcogenide glasses were recorded using DSC instrument. Fig. 3 shows typical DSC curves of glass samples. $T_{\mathrm{g}}$ and glass onset crystallization temperature $\left(T_{\mathrm{x}}\right)$ can be obtained from these curves. Specific values are listed in Table 1 . The $T_{\mathrm{g}}$ values of $\mathrm{Ge}-\mathrm{Ga}-\mathrm{Te}-\mathrm{Ag}$ glasses are nearly the same with an increase of Ag content. However, the $T_{\mathrm{g}}$ value of $\mathrm{Ge}-\mathrm{Ga}-\mathrm{Te}-\mathrm{AgI}$ glass increases with the addition of AgI. This behavior may be caused by silver atoms which locate at the end of long chains and form their own connected structure instead of opening the network of $\mathrm{GeTe}_{4}$ tetrahedral or $\mathrm{GaTe}_{3}$ triangle units. The bond energy of $\mathrm{Te}-\mathrm{Ag}(9.46$ $\mathrm{kJ} / \mathrm{mol}$ ) [15] is too small to influence the total bond energy of glasses. Therefore, the $T_{\mathrm{g}}$ values of $\mathrm{Ge}-\mathrm{Ga}-\mathrm{Te}-\mathrm{Ag}$ glasses are almost the same. Given the chain-terminating function of I atoms, the addition of $\mathrm{AgI}$ opens up the network of $\mathrm{GeTe}_{4}$ tetrahedral or $\mathrm{GaTe}_{3}$ triangle units. Owing to its high electronegativity, I atoms capture the electrons from Te atoms. The bond energy of Te-I (198 $\mathrm{kJ} / \mathrm{mol})$ is larger than $\mathrm{Ge}-\mathrm{Te}(171.3 \mathrm{~kJ} / \mathrm{mol})$ and $\mathrm{Ga}-\mathrm{Te}(162.8 \mathrm{~kJ} / \mathrm{mol})$ bonds. The total bond energy of glass increases with an increase of AgI. As a result, the $T_{\mathrm{g}}$ value of $\mathrm{Ge}-\mathrm{Ga}-\mathrm{Te}-\mathrm{AgI}$ glass increases gradually. The bond energy can be calculated using the following formula [16]: 


$$
D(A-B)=[D(A-A) * D(B-B)]^{0.5}+30\left(\chi_{A}-\chi_{B}\right)^{2}
$$

where, $\chi_{A}$ and $\chi_{B}$ are the electronegativity of the atoms $\mathrm{A}$ and $\mathrm{B}$, respectively. $D(A-A)$ and $D(B-B)$ are the bond energy of A-A and B-B bonds, respectively. The values of chemical bond energy are shown in Table 2.
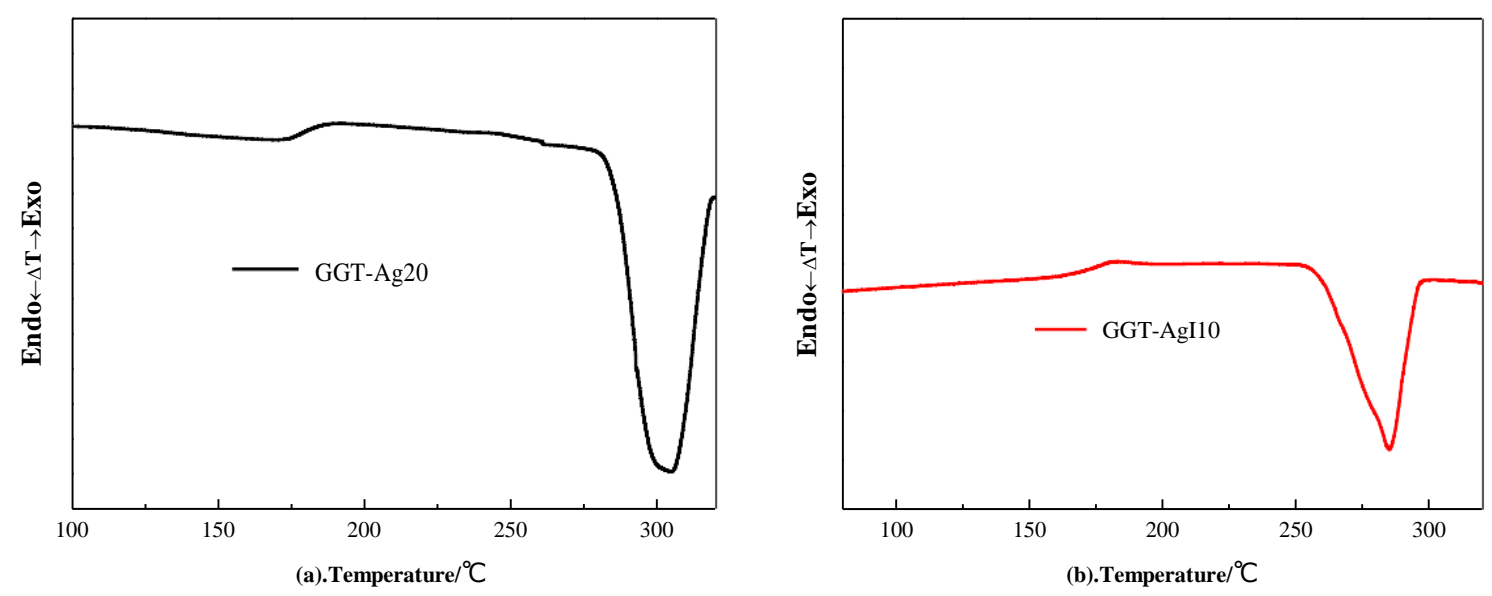

Fig. 3. DSC curves of typical glass samples: (a) $\left(\mathrm{Ge}_{15} \mathrm{Ga}_{10} \mathrm{Te}_{75}\right)_{80}(\mathrm{Ag})_{20}$ and (b) $\left(\mathrm{Ge}_{15} \mathrm{Ga}_{10} \mathrm{Te}_{75}\right)_{90}(\mathrm{AgI})_{10}$.

$\Delta \mathrm{T}$, the difference between $T_{\mathrm{x}}$ and $T_{\mathrm{g}}$, is usually used to assess the thermal stability of chalcogenide glass. From Table 1, the largest $\Delta \mathrm{T}$ values of $\mathrm{Ge}-\mathrm{Ga}-\mathrm{Te}-\mathrm{Ag}$ and $\mathrm{Ge}-\mathrm{Ga}-\mathrm{Te}-\mathrm{AgI}$ glasses are $110^{\circ} \mathrm{C}$ and $107^{\circ} \mathrm{C}$, corresponding to $\left(\mathrm{Ge}_{15} \mathrm{Ga}_{10} \mathrm{Te}_{75}\right)_{80}(\mathrm{Ag})_{20}$ and $\left(\mathrm{Ge}_{15} \mathrm{Ga}_{10} \mathrm{Te}_{75}\right)_{90}(\mathrm{AgI})_{10}$ glass samples, respectively. As a whole, the thermal performance of $\mathrm{Ge}-$ $\mathrm{Ga}-\mathrm{Te}-\mathrm{Ag}$ glass system is superior to that of $\mathrm{Ge}-\mathrm{Ga}-\mathrm{Te}-\mathrm{AgI}$ glass system.

Table 1

Thermal parameters of $\mathrm{Ge}-\mathrm{Ga}-\mathrm{Te}-\mathrm{Ag}$ and $\mathrm{Ge}-\mathrm{Ga}-\mathrm{Te}-\mathrm{AgI}$ glass samples.

\begin{tabular}{cccc}
\hline Compositions & $T_{\mathrm{g}} /{ }^{\circ} \mathbf{C}$ & $T_{\mathrm{x}} /{ }^{\circ} \mathbf{C}$ & $\Delta \mathbf{T} /{ }^{\circ} \mathbf{C}$ \\
\hline GGT-Ag10 & 176 & 284 & 108 \\
GGT-Ag20 & 175 & 285 & 110 \\
GGT-Ag30 & 175 & 280 & 105 \\
GGT-Ag40 & 176 & 279 & 103 \\
GGT-AgI10 & 152 & 259 & 107 \\
GGT-AgI20 & 163 & 265 & 102 \\
GGT-AgI30 & 166 & 263 & 97 \\
GGT-AgI40 & 168 & 266 & 98 \\
\hline
\end{tabular}

Table 2

Bond energy values of possible bonds.

\begin{tabular}{cc}
\hline Bond & Bond energy $(\mathrm{kJ} / \mathrm{mol})$ \\
\hline $\mathrm{Ge}-\mathrm{Ge}$ & 163 \\
$\mathrm{Te}-\mathrm{Te}$ & 235 \\
$\mathrm{Ge}-\mathrm{Te}$ & 171 \\
$\mathrm{Ga}-\mathrm{Te}$ & 163 \\
$\mathrm{Te}-\mathrm{I}$ & 198 \\
$\mathrm{Ag}-\mathrm{Te}$ & 9.46 \\
\hline
\end{tabular}




\subsection{IR spectra analysis}

The IR optical transmission spectra of these glasses are shown in Fig. 4. All glass samples have wide IR windows, and the IR cut-off wavelengths reach above $25 \mu \mathrm{m}$. The transmittance sharply declines when the wavelength is beyond $20 \mu \mathrm{m}$. The reason may be the multi-phonon absorption produced by $\mathrm{Ge}-\mathrm{Te}$ bond vibration [17]. With an increase of $\mathrm{Ag}$ or $\mathrm{AgI}$, the transmittance of $\mathrm{Ge}-\mathrm{Ga}-\mathrm{Te}-\mathrm{Ag}$ glass system deteriorates, whereas that of $\mathrm{Ge}-\mathrm{Ga}-\mathrm{Te}-\mathrm{AgI}$ glass system ameliorates. The decrease of transmittance with an increase of $\mathrm{Ag}$ is attributed to the disorder caused by $\mathrm{Ag}$ atoms. Halide, as a modifier doping into $\mathrm{Ge}-\mathrm{Ga}-\mathrm{Te}$ glass, improves the anti-crystallization ability and the transmittance of $\mathrm{Ge}-\mathrm{Ga}-\mathrm{Te}-\mathrm{AgI}$ glasses. Some absorption peaks can be observed in Fig. 4. The peak at $9.9 \mu \mathrm{m}$ results from $\mathrm{Si}-\mathrm{O}$ covalent bond vibration [9]. The peak at $15-20 \mu \mathrm{m}$ is ascribed to the presence of oxygen contamination, such as $\mathrm{Ge}-\mathrm{O}$ or $\mathrm{Ga}-\mathrm{O}$ bond vibrations [7-18]. The intensity of absorption peak depends on the purity of the starting elements. To eliminate these absorption peaks aroused by oxide impurities, a distilling method with 400 ppm Mg was adopted. The IR spectra of purified glasses are shown in Fig. 5. With the help of $\mathrm{Mg}$, the glasses have flat and wide IR optical transmission windows.
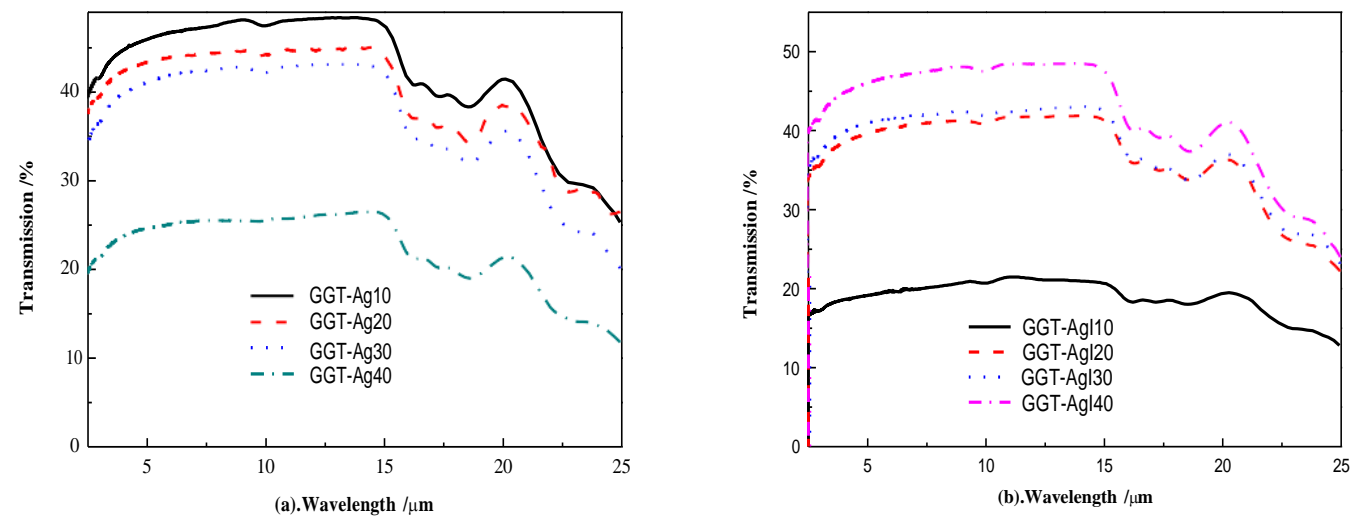

Fig. 4. IR transmission spectra of glass samples: (a) $\left(\mathrm{Ge}_{15} \mathrm{Ga}_{10} \mathrm{Te}_{75}\right)_{100-\mathrm{x}}(\mathrm{Ag})_{\mathrm{x}}$ and (b) $\left(\mathrm{Ge}_{15} \mathrm{Ga}_{10} \mathrm{Te}_{75}\right)_{100-\mathrm{x}}(\mathrm{AgI})_{\mathrm{x}}$
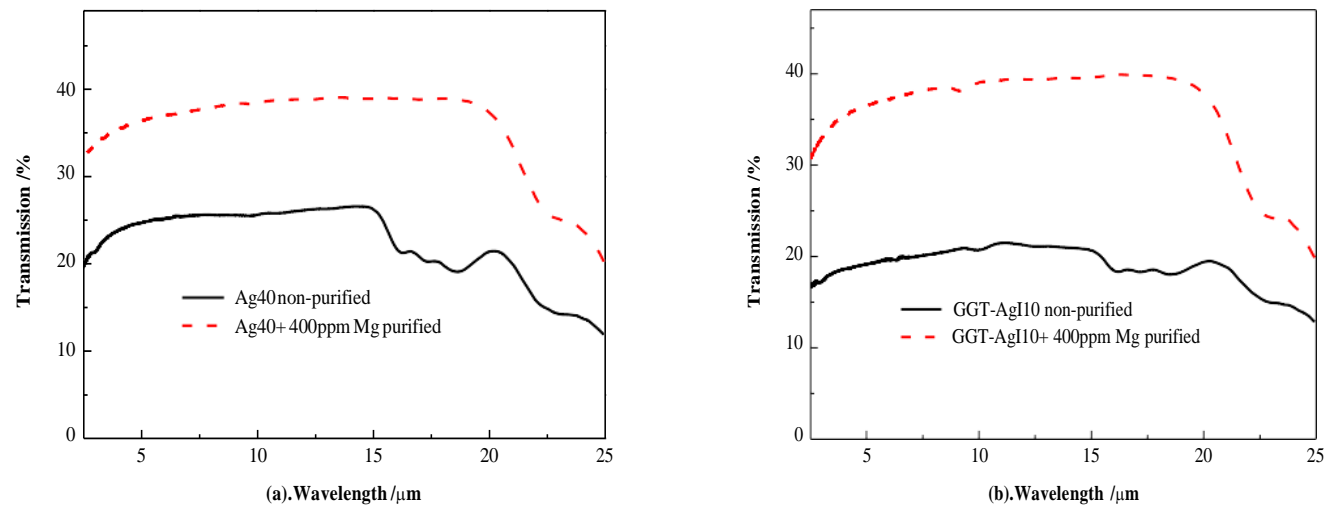

Fig. 5. IR spectra of purified glasses: (a). $\left(\mathrm{Ge}_{15} \mathrm{Ga}_{10} \mathrm{Te}_{75}\right)_{60}(\mathrm{Ag})_{40}$ and (b). $\left(\mathrm{Ge}_{15} \mathrm{Ga}_{10} \mathrm{Te}_{75}\right)_{90}(\mathrm{AgI})_{10}$.

\subsection{Near-IR absorption spectra and optical band gap}


The near-IR absorption spectra of $\mathrm{Ge}-\mathrm{Ga}-\mathrm{Te}-\mathrm{Ag}$ and $\mathrm{Ge}-\mathrm{Ga}-\mathrm{Te}-\mathrm{AgI}$ glasses are shown in Fig. 6. With an increase of $\mathrm{Ag}$, the absorption cut-off edge of $\mathrm{Ge}-\mathrm{Ga}-\mathrm{Te}-\mathrm{Ag}$ glass system shifts to the long wavelength region. On the contrary, the absorption cut-off edge of $\mathrm{Ge}-\mathrm{Ga}-\mathrm{Te}-\mathrm{AgI}$ glass system shifts to the short wavelength region with an increase of AgI. These behaviors may be attributed to the high electronegativity of I atoms, which make the width of the forbidden band broader. Eventually, this results in the blue shift of the $\mathrm{Ge}-\mathrm{Ga}-\mathrm{Te}-\mathrm{AgI}$ glass system. Elemental $\mathrm{Ag}$ and I show positive and negative effects on the glasses, respectively. Consequently, by combining two elements together, such as AgI, the effect on the glasses is determined by I atoms [19].
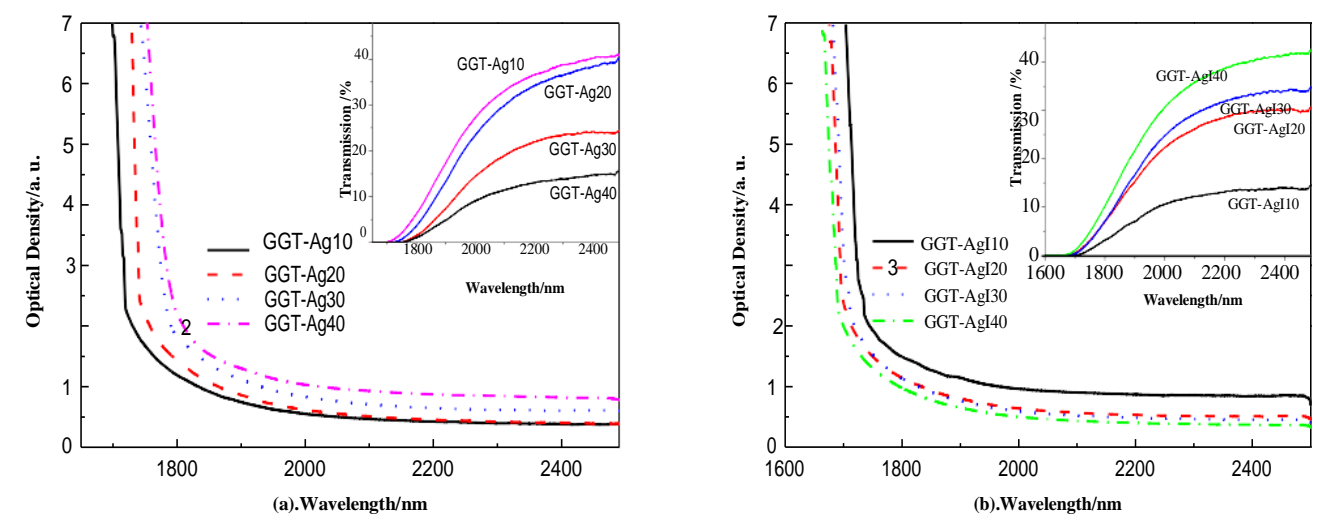

Fig. 6. Absorption spectra of glass samples. Inserts show the corresponding Vis-IR transmission spectra: (a)

$\left(\mathrm{Ge}_{15} \mathrm{Ga}_{10} \mathrm{Te}_{75}\right)_{100-\mathrm{x}}(\mathrm{Ag})_{\mathrm{x}}$ and (b) $\left(\mathrm{Ge}_{15} \mathrm{Ga}_{10} \mathrm{Te}_{75}\right)_{100-\mathrm{x}}(\mathrm{AgI})_{\mathrm{x}}$.

The function relationship between absorption coefficient $\alpha(\omega)$ and optical band gap $E_{\text {opt }}$ is given by Tauc equation [20]:

$$
\alpha(\omega) \cdot \hbar \omega=B\left(\hbar \omega-E_{\text {opt }}\right)^{\mathrm{m}}
$$

where $\alpha$ is the absorption coefficient, which is determined as $\alpha=2.303 \mathrm{~A} / \mathrm{d}$ (A is the optical density, $\mathrm{d}$ is the thickness of the glass sample), $E_{\text {opt }}$ is the optical band gap, $\hbar$ is Plank constant, $\omega$ is the incident light angular frequency, and $\mathrm{m}$ is a parameter that can determine the transition type of absorption edge. For amorphous glass materials, the direct and indirect transitions correspond to $\mathrm{m}=1 / 2$ and $\mathrm{m}=2$, respectively. $\mathrm{B}$ is a constant about local state in the band gap. B can be calculated with the following equation:

$$
B=\frac{(4 \pi / c) \sigma_{0}}{n_{0} \Delta E}
$$

where $\mathrm{c}$ is the light speed in vacuum, $\sigma_{0}$ is the electrical conductivity under absolute zero, $\mathrm{n}_{0}$ is the static refractive index, and $\Delta \mathrm{E}$ is the local state tail width. Fig. 7 and Fig. 8 correspond to the direct and indirect band gaps of glasses, respectively. For $\mathrm{Ge}-\mathrm{Ga}-\mathrm{Te}-\mathrm{Ag}$ glasses, $E_{\text {opt }}$ decreases with an increase of Ag. However, an increase of $\mathrm{AgI}$ can broaden the optical band gap of $\mathrm{Ge}-$ $\mathrm{Ga}-\mathrm{Te}-\mathrm{AgI}$ glasses. Fig. 9 shows the tendency of $E_{\text {opt }}$ of these glasses. In fact, the influence of $\mathrm{Ag}$ and I atoms on $E_{\text {opt }}$ of glasses are totally opposite. The electrophilic character of $\mathrm{I}^{-}$in $\mathrm{Ge}-\mathrm{Ga}-\mathrm{Te}-\mathrm{AgI}$ glasses plays beneficial roles of trapping lone pair electrons from $\mathrm{Te}$ atoms, and exciting the electrons from filled to empty states. In chalcogenide glass material, the conduction band is formed by the empty orbits, whereas the valence band is formed by lone pair electrons. With an increase of AgI, the conduction band is hardly affected, but the valence band decreases. 
Consequently, the optical band gap is broader and the effect of I supersedes that of Ag. $E_{\text {opt }}$ decreases with an increase of Ag. This can be attributed to structural transformation. Ag atoms enter into the glass structure and forme their own connected structure [21]. In this constrained network structure, Ag causes an increase in disorder and decreases the optical band gap effectively. The values of optical band gap of all glass samples are listed in Table 3 .
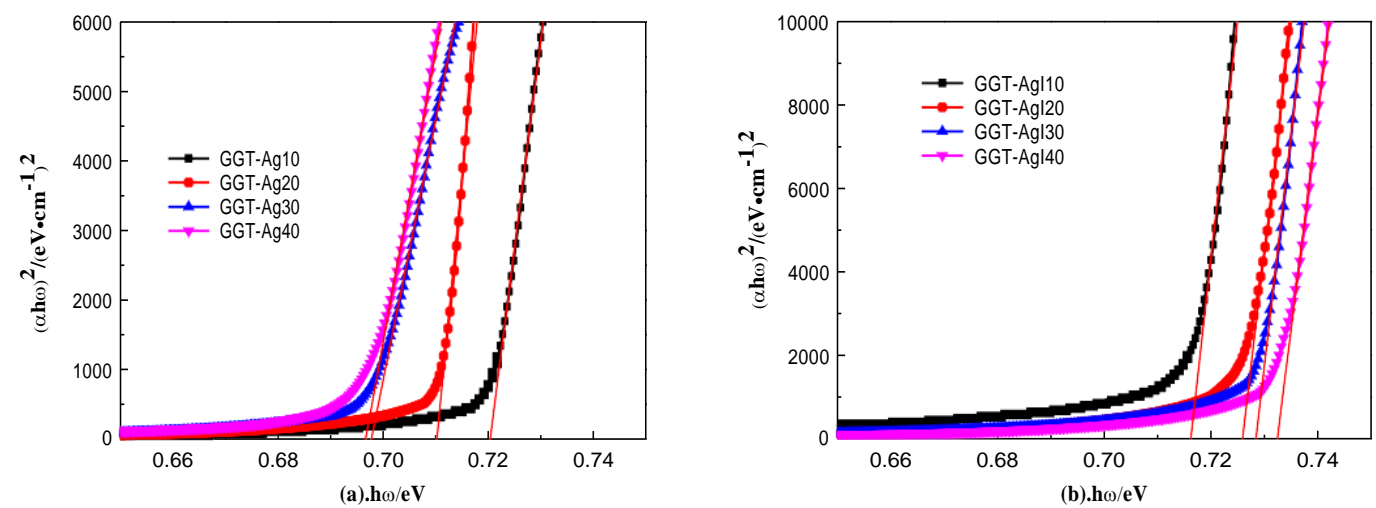

Fig. 7. Relationship between $(\alpha \bullet \hbar \omega)^{2}$ and $\hbar \omega$ for glass samples: (a) $\left(\mathrm{Ge}_{15} \mathrm{Ga}_{10} \mathrm{Te}_{75}\right)_{100-\mathrm{x}}(\mathrm{Ag})_{\mathrm{x}}$ and (b) $\left(\mathrm{Ge}_{15} \mathrm{Ga}_{10} \mathrm{Te}_{75}\right)_{100-\mathrm{x}}(\mathrm{AgI})_{\mathrm{x}}$
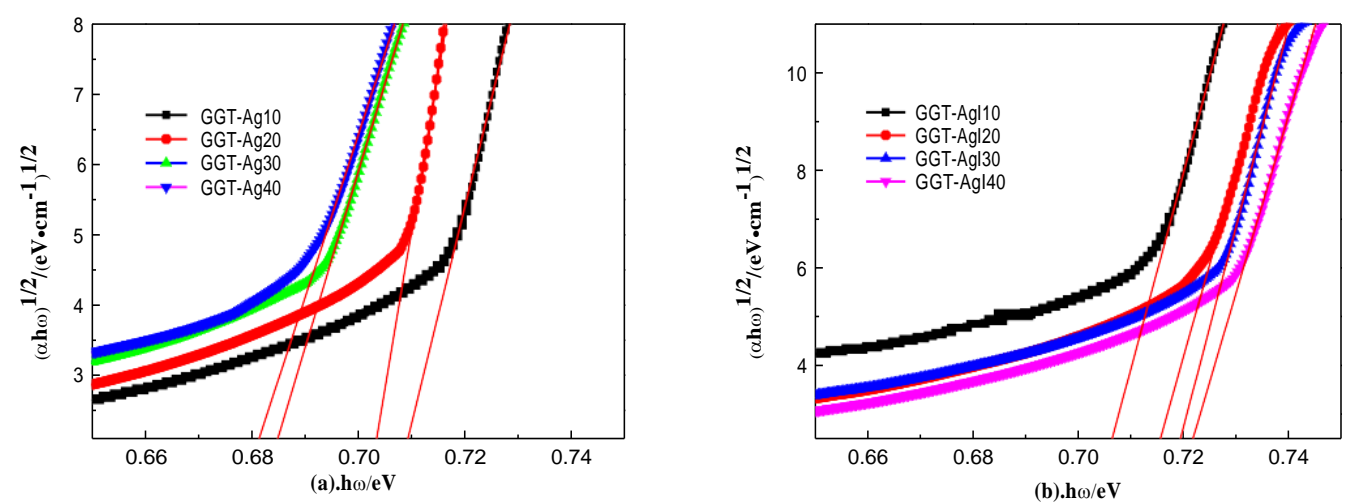

Fig. 8. Relationship between $(\alpha \bullet \hbar \omega)^{1 / 2}$ and $\hbar \omega$ for glass samples: (a) $\left(\mathrm{Ge}_{15} \mathrm{Ga}_{10} \mathrm{Te}_{75}\right)_{100-\mathrm{x}}(\mathrm{Ag})_{\mathrm{x}}$ and (b) $\left(\mathrm{Ge}_{15} \mathrm{Ga}_{10} \mathrm{Te}_{75}\right)_{100-\mathrm{x}}(\mathrm{AgI})_{\mathrm{x}}$.

Table 3

Optical band gap of $\mathrm{Ge}-\mathrm{Ga}-\mathrm{Te}-\mathrm{Ag}$ and $\mathrm{Ge}-\mathrm{Ga}-\mathrm{Te}-\mathrm{AgI}$ glasses.

\begin{tabular}{|c|c|c|c|}
\hline Compositions & Thickness/cm & Direct-E $\mathrm{ept}_{\mathrm{opt}} /(\mathrm{eV})$ & Indirect- $\mathrm{E}_{\text {opt }} /(\mathrm{eV})$ \\
\hline GGT-Ag10 & 0.108 & 0.719 & 0.707 \\
\hline GGT-Ag20 & 0.104 & 0.709 & 0.702 \\
\hline GGT-Ag30 & 0.110 & 0.696 & 0.679 \\
\hline GGT-Ag40 & 0.105 & 0.695 & 0.675 \\
\hline GGT-AgI10 & 0.095 & 0.716 & 0.705 \\
\hline GGT-AgI20 & 0.104 & 0.725 & 0.715 \\
\hline GGT-AgI30 & 0.103 & 0.727 & 0.717 \\
\hline GGT-AgI40 & 0.103 & 0.731 & 0.719 \\
\hline
\end{tabular}



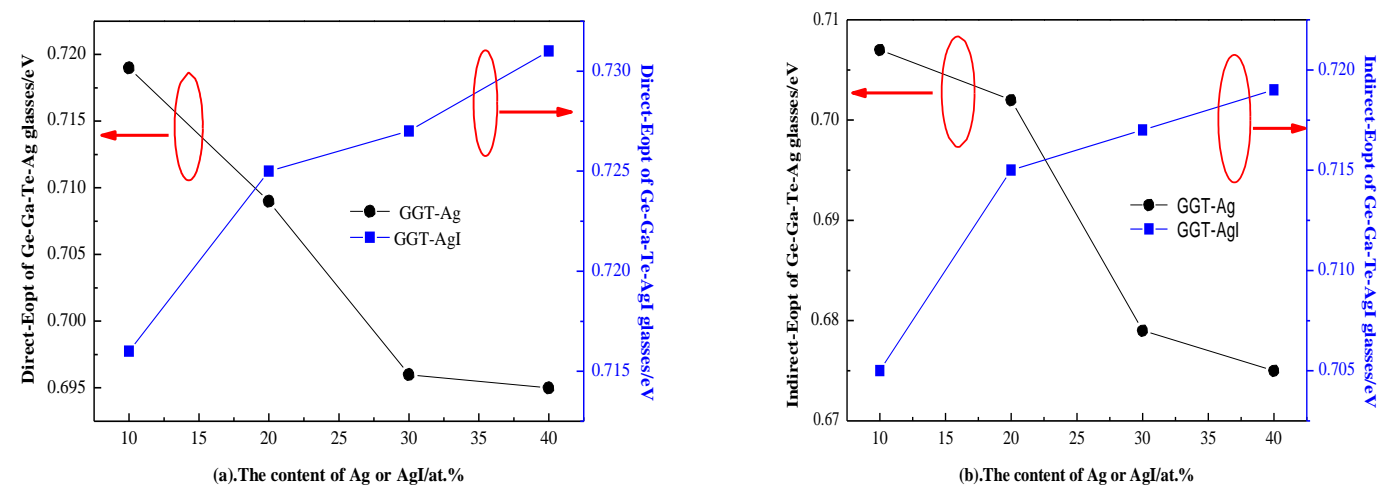

Fig. 9. Relationship between $E_{\text {opt }}$ and the content of Ag or AgI: (a) Direct optical band gap and (b) Indirect optical band gap.

\section{Conclusions}

In this study, $\mathrm{Ge}-\mathrm{Ga}-\mathrm{Te}-\mathrm{Ag}$ and $\mathrm{Ge}-\mathrm{Ga}-\mathrm{Te}-\mathrm{AgI}$ glass systems were prepared and investigated. Results indicate that these glasses possess good amorphous state and thermal stability. An increase of $\mathrm{Ag}$ content results in a decrease in the optical band gap of $\mathrm{Ge}-\mathrm{Ga}-\mathrm{Te}-\mathrm{Ag}$ glasses, whereas an increase of AgI content increases the optical band gap of $\mathrm{Ge}-\mathrm{Ga}-\mathrm{Te}-\mathrm{AgI}$ glasses. The IR optical windows of these glasses are wide and flat, ranging from $1.8 \mu \mathrm{m}$ to $20 \mu \mathrm{m}$. No obvious absorption peak exists after the purification method, which indicates that these glasses are promising material for far-IR applications.

\section{Acknowledgment}

This work was financially supported by the Natural Science Foundation of China (Grant Nos. 61435009, 61177087, and 61377099), National Program on Key Basic Research Project (973 Program) (Grant No. 2012CB722703), International Science \& Technology Cooperation Program of China (Grant No. 2011DFA12040), Scientific Research Fund of Zhejiang Provincial Education Department (R1101263), Natural Science Foundation of Ningbo (Grant No. 2013A610118), Teaching and Research Award Program for Outstanding Young Teachers in Higher Education Institutions of MOE, P.R.C. Ningbo Optoelectronic Materials and Devices Creative Team (2009B21007), and Scientific Research Foundation of Graduate School of Ningbo University. This work was also sponsored by K. C. Wong Magna Fund of Ningbo University, the Outstanding (Postgraduate) Dissertation Growth Foundation of Ningbo University (Grant No. PY2014014), and the Scientific Research Foundation of Graduate School of Ningbo University. 


\section{References}

[1] X. Zhang, G. Fonteneau, J. Lucas, Tellurium halide glasses. New materials for transmission in the 8-12 $\mu \mathrm{m}$ range, J. Non-Cryst. Solids 104 (1988) 38-44.

[2] J. Lucas, X. Zhang, The tellurium halide glasses, J. Non-Cryst. Solids 125 (1990) 1-16.

[3] S. Danto, P. Houizot, C. Boussard-Pledel, A Family of Far-Infrared-Transmitting Glasses in the Ga-Ge-Te System for Space Applications, Adv. Funct. Mater. 16 (2006) 1847-1852.

[4] G.R. Elliott, D.W. Hewak, G.S. Murugan, Chalcogenide glass microspheres; their production, characterization and potential, Opt. Express 15 (2007) 17542-17553.

[5] A.A. Wilhelm, C. Boussard-Pledel, Q. Coulombier, Development of Far-Infrared-Transmitting Te Based Glasses Suitable for Carbon Dioxide Detection and Space Optics, Adv. Mater. 19 (2007) 3796-3800.

[6] S. Maurugeon, B. Bureau, C. Boussard-Plédel, Te-rich Ge-Te-Se glass for the $\mathrm{CO}_{2}$ infrared detection at $15 \mu \mathrm{m}$, J. Non-Cryst. Solids 355 (2009) 2074-2078.

[7] S. Sen, E. Gjersing, B. Aitken Physical properties of $\mathrm{Ge}_{\mathrm{x}} \mathrm{As}_{2 \mathrm{x}} \mathrm{Te}_{100-3 \mathrm{x}}$ glasses and Raman spectroscopic analysis of their short-range structure, J. Non-Cryst. Solids 356 (2010) 2083-2088.

[8] X. Wang, Q. Nie, G. Wang, Investigations of Ge-Te-AgI chalcogenide glass for far-infrared application, Spectrochimica Acta Part A: Molecular and Biomolecular Spectroscopy 86 (2012) 586-589.

[9] C. Cheng, X. Wang, T. Xu, Novel Ge-Ga-Te-CsBr glass system with ultrahigh resolvability of halide, Spectrochimica Acta Part A: Molecular and Biomolecular Spectroscopy 150 (2015) 737741.

[10] S. Cui, C. Boussard-Plédel, J. Lucas, Te-based glass fiber for far-infrared biochemical sensing up to $16 \mu \mathrm{m}$, Opt. Express 22 (2014) 21253-21262.

[11] Y. He, X. Wang, Q. Nie, Optical properties of $\mathrm{Ge}-\mathrm{Te}-\mathrm{Ga}$ doping $\mathrm{Al}$ and $\mathrm{AlCl}_{3}$ far infrared transmitting chalcogenide glasses, Infrared Physics \& Technology 58 (2013) 1-4.

[12] S. Maurugeon, B. Bureau, C. Boussard-Plédel, Te-rich Ge-Te-Se glass for the $\mathrm{CO}_{2}$ infrared detection at $15 \mu \mathrm{m}$, J. Non-Cryst. Solids 355 (2009) 2074-2078.

[13] K. Ramesh, S. Asokan, K. Sangunni, Glass formation in germanium telluride glasses containing metallic additives, J. Phys. Chem. Solids 61 (2000) 95-101.

[14] J. Sun, Q. Nie, X. Wang, Glass formation and properties of Ge-Te-BiI ${ }_{3}$ far infrared transmitting chalcohalide glasses, Spectrochimica Acta Part A: Molecular and Biomolecular Spectroscopy 79 (2011) 904-908.

[15] Q. Nie, G. Wang, X. Wang, Glass formation and properties of $\mathrm{GeTe}_{4}-\mathrm{Ga}_{2} \mathrm{Te}_{3}-\mathrm{AgX}(\mathrm{X}=\mathrm{I} / \mathrm{Br} / \mathrm{Cl})$ far infrared transmitting chalcohalide glasses, Optics Communications 283 (2010) 4004-4007.

[16] L. Pauling, The Nature of Chemical Bonds. (Cornell University, New York, 1960), p.175.

[17] C. Quémard, F. Smektala, V. Couderc, Chalcogenide glasses with high non linear optical properties for telecommunications, J. Phys. Chem. Solids 62 (2001) 1435-1440.

[18] K.S. Andrikopoulos, S.N. Yannopoulos, A.V. Kolobov, Raman scattering study of GeTe and $\mathrm{Ge}_{2} \mathrm{Sb}_{2} \mathrm{Te}_{5}$ phase-change materials, J. Phys. Chem. Solids 68 (2007) 1074-1078.

[19] S. Cui, D. Le Coq, C. Boussard-Plédel, Electrical and optical investigations in Te-Ge-Ag and Te-Ge-AgI chalcogenide glasses, J. Alloys Compd. 639 (2015) 173-179.

[20] A. Kolobov, P. Fons, J. Tominaga, Crystallization-induced short-range order changes in amorphous GeTe, J. Phys.: Condens. Matter 16 (2004) S5103. 
[21] M. Sakurai, F. Kakinuma, E. Matsubara, Partial structure analysis of amorphous $\mathrm{Ge}_{15} \mathrm{Te}_{80} \mathrm{M}_{5}(\mathrm{M}=$ $\mathrm{Cu}, \mathrm{Ag}$ and In), J. Non-Cryst. Solids 312 (2002) 585-588. 